Research Article

\title{
Considering Source-Charge-Storage Multiple Time Scale Cooperative Control Strategy
}

\author{
Tao Zheng $\mathbb{D}^{1}{ }^{1}$ Jing Cao, ${ }^{1}$ Yufeng Yang, ${ }^{1}$ and Hui Gao ${ }^{2}$ \\ ${ }^{1}$ State Grid Electric Power Research Institute Co. Ltd, Nanjing, Jiangsu 211106, China \\ ${ }^{2}$ Nanjing University of Posts and Telecommunications, Nanjing, Jiangsu 211106, China \\ Correspondence should be addressed to Tao Zheng; 2090035109@qq.com
}

Received 3 February 2021; Revised 28 April 2021; Accepted 19 May 2021; Published 27 May 2021

Academic Editor: Raffaele Carli

Copyright (c) 2021 Tao Zheng et al. This is an open access article distributed under the Creative Commons Attribution License, which permits unrestricted use, distribution, and reproduction in any medium, provided the original work is properly cited.

In order to achieve the optimization of power consumption mode, improve user power efficiency, and realize the coordination of power supply and demand, considering the advantages of distributed energy and energy storage, a source-charge-storage multitime-scale coordinated control strategy is proposed. According to the needs of the hybrid energy system, we analyze the complementary potential of the hybrid energy system from the output side and analyze the response priority mechanism of the integrated energy system equipment, taking the economic cost and pollutant gas emissions as the objective function, economy, environment, and system. This is a constrained source-load-storage multiobjective joint optimization and adjustment model, which is solved by a multi-time-scale cooperative control strategy. Finally, a calculation example is used to verify the feasibility of the proposed method and provide technical support for the coordinated and optimized operation of "source-load-storage."

\section{Introduction}

After the industrial revolution, energy plays a crucial role in the development of a country, and it is also an important guarantee for national strategic security $[1,2]$. China has invested trillions of dollars in the construction of peaking power plants, but they can only meet the temporary peak electricity consumption. With the development of urbanization, to meet the growing load demand for a long time, it is necessary to adjust the source, load, and storage and make rational use of social resources. During the peak of summer, the government and grid companies have to take orderly electric utilization measures to cope with short-term spikes. Therefore, how to carry out simulation optimization research on integrated energy cooperative control strategy, so as to realize the optimization of power consumption mode, improve the efficiency of electricity consumption, and achieve the coordination of power supply and demand, is the focus of future research.

Zheng et al. [3] use distributed photovoltaic sets to optimize scheduling, which can improve the economy of distributed photovoltaic power generation. Gao Hui et al. [4] propose an optimal control model for multiple interaction and coordination of source networks to cope with the uncertainty and randomness of power grid caused by distributed generation. Li et al. [5] mainly consider the characteristics of wind storage for power generation and use the method of dynamic weighting to coordinate and optimize the wind storage. Diao et al. [6] proposed a comprehensive energy coordination optimization method involving energy storage, which can effectively increase the absorption of new energy. Ou et al. [7] consider the influence of seasons on the operation of comprehensive energy, design different operation modes in different seasons, and make full use of the complementarity and coordination of source, charge, and storage. The above literatures mainly study the coordinated and optimized operation of comprehensive energy, but the factors considered in the comprehensive energy optimization are relatively single, and the coordination and complementarity of multisource operation, the optimization of multi-time-scale, and the influence of energy storage on the power grid are not comprehensively considered. In the first part of this paper, the research status of comprehensive energy is analyzed. In the second part, the complementary potential of the hybrid energy system is studied from the output side according to the demand of the hybrid energy 
system. In the third part of this paper, the objective function of economic cost and pollution gas emission is established. In the fourth part of the paper, the multi-time-scale cooperative control strategy is used to solve the problem. In the last part of the paper, an example is used to verify and analyze the multi-time-scale source-storage-load multiobjective joint optimization and regulation results.

\section{Multisource Synergy and Complementarity Potential Analysis}

The integrated energy system is a large-scale complex system composed of power system, natural gas system, and heating (cooling) system, which includes energy utilization and conversion equipment with large scale and different performance. At the same time, there are a large number of coupling forms of electricity, gas, and heat (cooling) in different forms on the energy supply and energy use side. Its system architecture is shown in Figure 1.

According to the demand of the hybrid energy system, the complementary potential of the hybrid energy system is studied from the output side. Based on the real-time cooling, thermal and electrical load and related output data, the output coordination, and complementarity potential of the hybrid energy consisting of cooling, thermal and electrical load were analyzed. Figure 2 shows the matching of typical daily load and output in winter. The thermal load required in typical days in winter is relatively large, while the electrical load is relatively small. From the output side, photovoltaic output gradually increases from $7^{\circ}$ 'clock to about $10: 30$, and during this period, the thermal load demand and hot water load demand are relatively high, but the electrical load demand is relatively low. Therefore, in this period of time, we can make full use of photovoltaic to supply part of the charge, and the remaining part is supplied by micro-gasturbine and mains supply. The thermal load and hot water load need to be supplied by optothermal and heat pumps, CCHP systems, and regenerative boilers.

Figure 3 shows the matching of typical daily load and output in summer. As can be seen from the figure, the demand for cooling energy remains high during the whole 24 hours in summer, while the electricity and hot water loads are relatively low. During the period from 17:00 to 5:00, photovoltaic basically does not function, but the hot water load during this period is relatively large, and the CCHP system, heat pump, and regenerative boiler offer this part of heat energy. The electrical load between $0: 00$ and 5:00 is relatively low, which also belongs to the valley period of the power grid, so the electrical load can be supplied by the mains supply. During this period, the mains supply can also be used for refrigeration and production of domestic hot water and storage for peak use.
To sum up, in an integrated energy system, energy supply can achieve a good complementary effect under different seasonal demands. When the energy supply is sufficient, the excess heat, cold, and electric energy can be stored for peak use. When cold and hot energy consumption is in the trough, energy can be stored; when the electricity consumption is low, the excess electric energy can be stored, and the thermal energy and cold energy generated during this period can also be directly supplied to the load or stored for peak use. The coordination and complementarity of cold, hot, and electric sources can minimize the use of mains supply under the premise of meeting the current load demand.

\section{Multiobjective Joint Optimization and Regulation Model of Source-Load-Storage}

Since buildings are the main energy users in the regional integrated energy system, the demand response characteristics of buildings are further added to the multiobjective joint optimization and regulation model of "source-storageload" in the regional integrated energy system, so as to further improve the economy and environmental protection of the regional integrated energy system. In the multiobjective joint optimization and regulation model of "source-storage-load," "source" represents electricity and natural gas, "storage" represents the energy storage on the demand side of the buildings and the actual energy storage system, and "Charge" represents the cooling, thermal, and electrical loads in the regional integrated energy system $[8,9]$.

3.1. The Objective Function. In this paper, based on the heat storage characteristics of the buildings and energy conservation, the heat balance equation of the building is obtained, which is as follows:

$$
\Delta Q=\rho \times C \times V \times \frac{\mathrm{d} T_{\text {in }}}{\mathrm{d} \tau},
$$

where $\rho$ represents air density, and the unit is $1.29 \mathrm{Kg} / \mathrm{m}^{3} ; C$ represents the specific heat capacity of air, and the unit is $1.003 \mathrm{~kJ} /\left(\mathrm{kg}^{*} \mathrm{~K}\right) ; \Delta Q$ represents indoor heat variation, and the unit is $J ; V$ represents the volume of indoor air, and the unit is $\mathrm{m}^{3} ; \mathrm{d} T_{\text {in }} / \mathrm{d} \tau$ represents the rate of change of indoor temperature.

The main factors that affect the internal heat of a building are cold/heat dissipation caused by indoor and outdoor temperature differences, solar heat radiation, heating of human bodies, and equipment in the building and cooling/ thermal power output of refrigeration/thermal equipment. Taking cooling in summer as an example, the above equation can be expressed as

$$
k_{\text {wall }} \times F_{\text {wall }} \times\left(T_{\text {out }}-T_{\text {in }}\right)+k_{\text {win }} \times F_{\text {win }} \times\left(T_{\text {out }}-T_{\text {in }}\right)+I \times F_{\text {win }} \times S C+Q_{\text {in }}-Q_{c l}=\rho \times C \times V \times \frac{\mathrm{d} T_{\text {in }}}{\mathrm{d} \tau},
$$




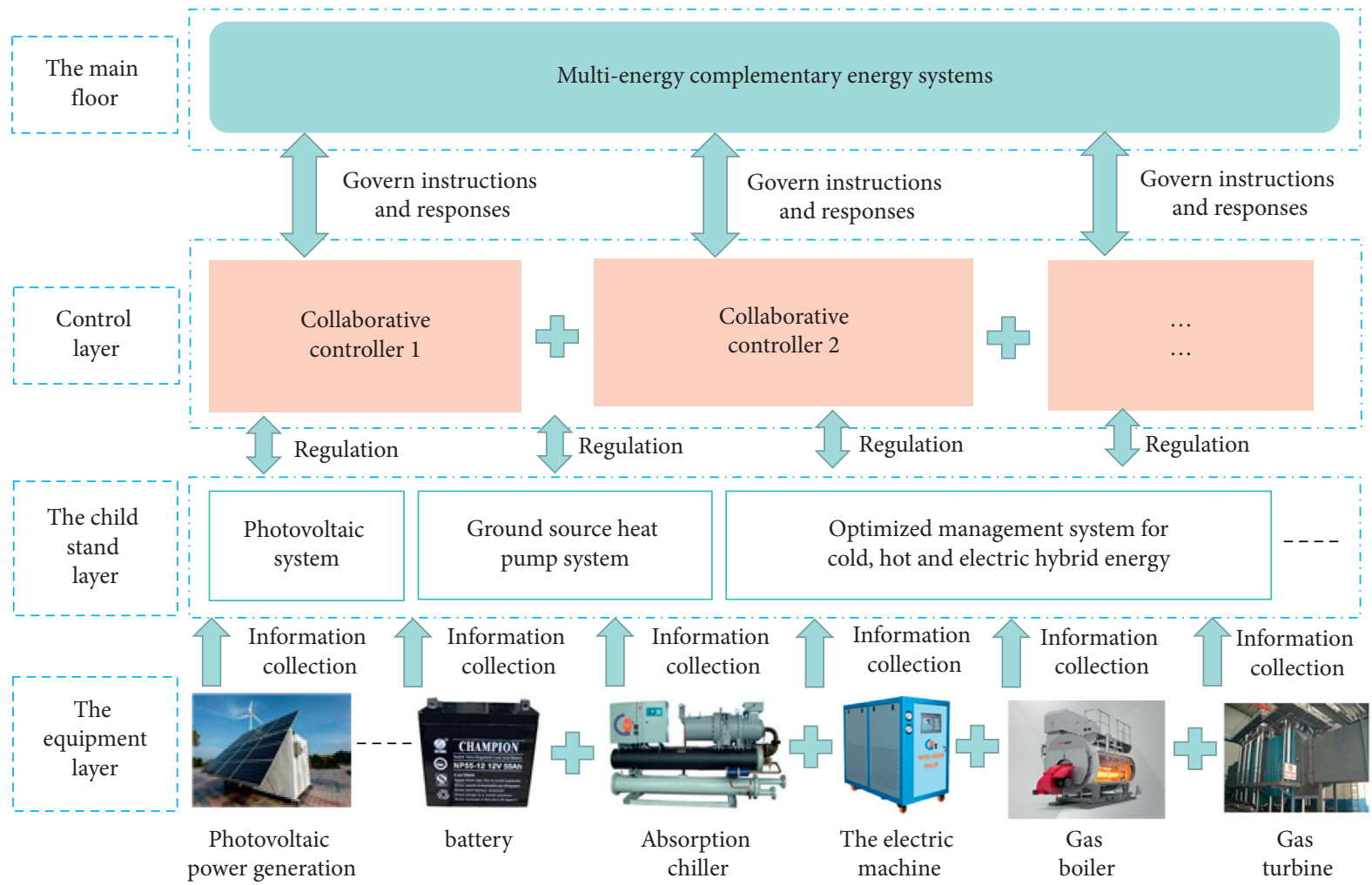

Figure 1: System architecture.

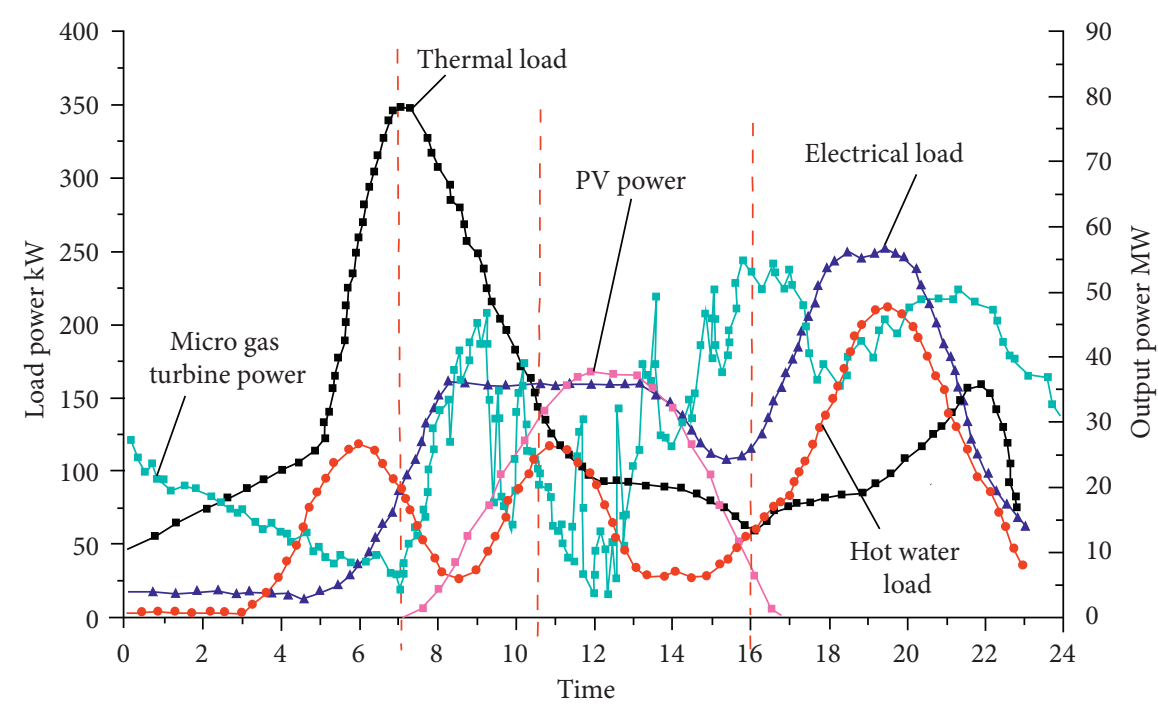

Figure 2: Matching of typical daily load and output in winter.

where $K_{\text {wall }}$ is the heat transfer coefficient of the building exterior wall, which represents the amount of heat passing through the wall in the temperature difference between indoor and outdoor for each degree per second during steady heat transfer, and the unit is $\mathrm{W} /\left(\mathrm{m}^{2} \cdot \mathrm{K}\right) ; F_{\text {wall }}$ is the area of building exterior wall, and the unit is $\mathrm{m}^{2} ;\left(T_{\text {out }}-T_{\text {in }}\right)$ is the temperature difference between indoor and outdoor, and the unit is ${ }^{\circ} \mathrm{C}$; $k_{\text {wall }} \times F_{\text {wall }} \times\left(T_{\text {out }}-T_{\text {in }}\right)$ represents heat transfer between building exterior wall and outdoor, and the unit is J. $k_{\text {win }}$ is the heat transfer coefficient of the exterior windows of the building, and the unit is $\mathrm{W} /\left(\mathrm{m}^{2} \cdot \mathrm{K}\right) ; F_{\text {win }}$ is the area of the exterior windows of the building, and the unit is $\mathrm{m}^{2} ; k_{\text {win }} \times$ $F_{\text {win }} \times\left(T_{\text {out }}-T_{\text {in }}\right)$ represents heat transfer between the exterior windows of the building and outdoor, and the unit is $J ; I$ is solar radiation power, representing the heat received per square meter per second when it is perpendicular to illumination, and the unit is $\mathrm{W} ; S C$ is the shading coefficient, and its value is related to whether there are sun visors and glass materials. $Q_{i n}$ is the heating power of indoor heat source, such as the heating of human body and electrical equipment, and 


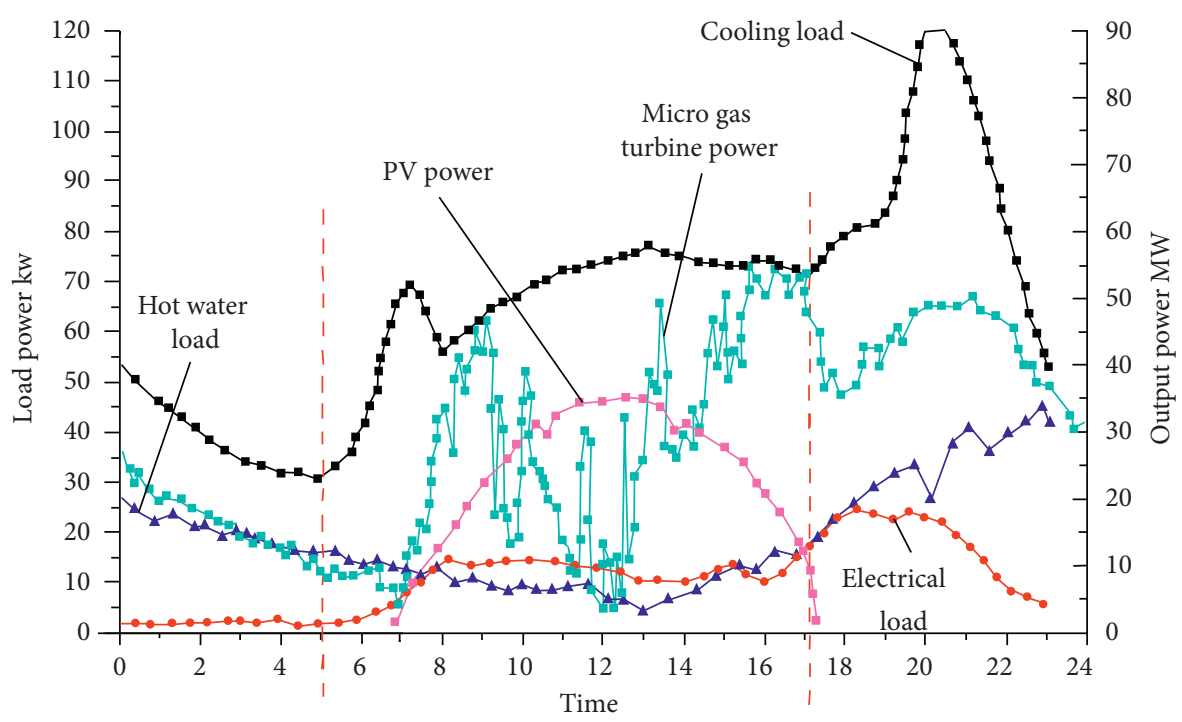

FIGURE 3: Matching of typical daily load and output in summer.

the unit is $W . Q_{c l}$ is the refrigeration power of the refrigeration equipment, and the unit is $\mathrm{W} ; \quad I \times F_{w i n} \times S C$ represents heat transmitted by solar thermal radiation, and the unit is $J$.

According to the mathematical relationship between the indoor temperature of the buildings and the refrigeration power of the refrigeration equipment, the refrigeration demand of the buildings should be adjusted within a certain range due to the heat storage characteristics of the buildings. The charge-discharge power based on the demand-side energy storage model of buildings is as follows $[10,11]$ :

$$
Q_{\mathrm{VSS}, t}=Q_{c l \text {, building, } t}-Q_{c l, \text { building, } t} \text {, }
$$

where $Q_{V S S, t}$ is the charge-discharge power of the demandside energy storage model, and the unit is $\mathrm{W}$; the discharge is positive, and the charge is negative; $Q_{c l \text {, building, } t}$ is the refrigeration power demand of the building without adjusting the indoor temperature, and the unit is $\mathrm{W} ; \mathrm{Q}_{c l \text {, building, } t}$ is the power requirement for building refrigeration to adjust the indoor temperature in order to maintain the temperature within the appropriate range, and the unit is $\mathrm{W}$.

The cost of electricity and gas purchase constitutes the economic cost of the regional comprehensive energy system. In order to improve the economy and environmental protection of the system, this paper takes the economic cost and the emission of polluted gas as the objective function, and the multiobjective function is shown as follows:

$$
\begin{aligned}
F_{1}(t) & =\min \text { COST }=C_{\text {elec }, t} \times P_{\text {elec }, t}+C_{\text {gas }, t} \times F_{\text {gas }, t}, \\
F_{2}(t) & =\min \text { EMISSION }=E_{\text {elec }}+E_{E C} \\
& =\sum_{i=1}^{N} E_{\text {elec }, i, t}+\sum_{j=1}^{n} E_{E C, j, t} \\
& =\sum_{i=1}^{N} e_{\text {elec }, i} \times P_{\text {elec }, t}+\sum_{j=1}^{n} \chi_{E C, j} \times L_{h, j, t},
\end{aligned}
$$

where $P_{\text {elec,t }}$ represents the electric power required by the regional integrated energy system at time $t$, and the unit is
$\mathrm{W} ; F_{\text {gas }, t}$ represents the natural gas required by the regional integrated energy system at time $t$, and the unit is $\mathrm{m}^{3} ; C_{\text {elec, } t}$ represents the power price of the grid at time $t$, and the unit is $¥ / \mathrm{kWh}$; $E_{\text {elec,i,t }}$ represents the discharge of the i-th pollutant gas from the power grid at time $t$, and the unit is $\mathrm{m}^{3}$; $C_{\text {gas }, t}$ is the price of natural gas at time $t$, and the unit is $¥ / \mathrm{kWh} ; N$ is the type of gas emitted from power grid, including $\mathrm{CO}_{2}, \mathrm{CO}, \mathrm{SO}_{2}$, and nitrogen oxides. $e_{\text {elec, } i}$ is the emission factor of the i-th pollution gas in the power grid; $E_{E C, j, t}$ is the discharge of the $\mathrm{j}$-th CCHP pollution gas at time $t$, and the unit is $\mathrm{m}^{3} ; n$ represents the number of CCHP in the regional integrated energy system; $L_{h, j, t}$ represents the thermal charge of the $\mathrm{j}$-th CCHP at time $t$, and the unit is $\mathrm{kWh} ; \chi_{E C, j}$ represents the emission factor of the $\mathrm{j}$-th CCHP pollution gas.

3.2. The Constraint. In addition to pursuing the maximum economic benefit of the system, the mixed energy system should also consider the atmospheric pollution caused by carbon dioxide and other gases, the capacity and efficiency limits of the energy supply and consumption equipment, and the operating limits of the electric/thermal system. Therefore, three constraints, that is, economy, environment, and system, need to be considered in this paper $[12,13]$ :

3.2.1. Economic Constraint. An allowable value of economic constraint was set in this paper, so that the sum of operation cost, equipment maintenance cost, operation cost, electricity purchase cost, and gas purchase cost is not greater than this set value.

$$
\xi_{\text {Fuel }}+\xi_{\mathrm{Om}}+\xi_{\text {Grid }}+\xi_{\text {Env }} \leq F_{\text {max }} .
$$

$\xi_{\text {Fuel }}, \xi_{\text {Om }}, \xi_{\text {Grid }}, F_{\text {max }}$, respectively, represent the maximum allowable sum of operation cost, equipment maintenance cost, operation cost, electricity purchase cost, and gas purchase cost, and the unit is $¥$. 
3.2.2. Environmental Constraints. The environmental constraints considered in this paper include emission constraint and carbon tax constraint. The emission of carbon dioxide, sulfur dioxide, and nitrogen oxides shall be less than or equal to the maximum allowable emission value.

$$
\left\{\begin{array}{l}
E_{\mathrm{CO}_{2}} \leq E_{\max _{\mathrm{CO}_{2}}}, \\
E_{\mathrm{SO}_{2}} \leq E_{\max _{\mathrm{SO}_{2}}}, \\
E_{\mathrm{N}_{\mathrm{X}} \mathrm{O}} \leq E_{\max _{\mathrm{N}_{\mathrm{X}} \mathrm{O}}}
\end{array}\right.
$$

where $E_{\max _{\mathrm{CO}_{2}}}$ is the maximum allowable value of carbon dioxide discharge, and the unit is $\mathrm{m}^{3} ; E_{\max _{\mathrm{SO}_{2}}}$ is the maximum allowable value of sulfur dioxide discharge, and the unit is $\mathrm{m}^{3} ; E_{\max _{N_{X} O}}$ is the maximum allowable value of nitrogen discharge, and the unit is $\mathrm{m}^{3}$.

The quantity of electricity purchased shall be less than or equal to the maximum allowable value of electricity purchase cost, and the quantity of gas purchased shall be less than or equal to the maximum allowable value of carbon tax cost.

$$
\left\{\begin{array}{l}
\xi_{\text {Fuel }} \leq F_{F \text { max }}, \\
\xi_{\text {Grid }} \leq F_{G \text { max }},
\end{array}\right.
$$

where $F_{F \max }$ is the maximum allowable value of electricity purchase cost, and the unit is $¥ ; F_{G \text { max }}$ is the maximum allowable of carbon tax cost, and the unit is $¥$.

3.2.3. System Constraints. The supply and demand balance constraint of electric/heat/cold is considered in this paper. Under the coordination of electricity storage, heat storage, and cold storage devices, the balance between electricity production and electricity consumption should be guaranteed within the energy station and the whole park, at the same time, to ensure the balance of the heat production and heat consumption and the balance of the cold production and cold consumption.

Electrical power constraints:

$$
p_{t, j}^{L}=\sum_{m_{p}} p_{t, j, m_{p}}^{\mathrm{OUT}}-\sum_{n_{p}} p_{t, j, n_{p}}^{I N}+P_{t, j}^{\mathrm{Buy}}+P_{t, j}^{\mathrm{dis}},
$$

Thermal power constraints:

$$
h_{t, j}^{L}=\sum_{m_{h}} h_{t, j, m_{h}}^{\mathrm{OUT}}-\sum_{n_{h}} h_{t, j, n_{h}}^{\mathrm{IN}}+H_{t, j}^{\mathrm{dis}} .
$$

Cold power constraints:

$$
c_{t, j}^{L}=\sum_{m_{c}} c_{t, j, m_{c}}^{\mathrm{OUT}}+C_{t, j}^{d i s},
$$

where $p_{t, j, n_{p}}^{I N}$ and $h_{t, j, n_{h}}^{I N}$ are, respectively, the heat consumed by the $\mathrm{n}_{\mathrm{p}}$-th power-cold conversion equipment and the electricity consumed by the $\mathrm{n}_{\mathrm{h}}$-th heat-cold conversion equipment in the energy station $j$ at time $t$, and the unit is $\mathrm{J} ; p_{t, j}^{L}, h_{t, j}^{L}, c_{t, j}^{L}$, respectively, represent the electrical, thermal, and cooling loads of energy station $j$ at time $t$, and the unit is $\mathrm{kWh} ; P_{t, j}^{\mathrm{Buy}}$ is the net electric quantity purchased at time $t$ and is the difference between electric quantity purchased and electric quantity sold, and the unit is kWh; $p_{t, j, m_{p}}^{\mathrm{OUT}}, h_{t, j, m_{h}}^{\mathrm{OUT}}, c_{t, j, m_{c}}^{\mathrm{OUT}}$ are, respectively, the output power of the $\mathrm{m}_{\mathrm{p}}$-th generating unit, the $\mathrm{m}_{\mathrm{h}}$-th generating unit, and the $\mathrm{m}_{\mathrm{c}}$-th generating unit in the energy station $j$ at time $t$, and the unit is $\mathrm{kWh} ; P_{t, j}^{d i s}, H_{t, j}^{d i s}, C_{t, j}^{d i s}$ are, respectively, the net discharge power, net heat release power, and net cold release power of the energy storage unit of the energy station at time $t$, and the unit is $\mathrm{kWh}$.

$$
\left\{\begin{array}{l}
P_{t, j}^{d i s}=p_{t, j}^{d i s} x_{t, j}^{p d i s}-p_{t, j}^{c h} x_{t, j}^{p c h} \\
H_{t, j}^{d i s}=h_{t, j}^{d i s} x_{t, j}^{h d i s}-h_{t, j}^{c h} x_{t, j}^{h c h} \\
C_{t, j}^{d i s}=c_{t, j}^{d i s} x_{t, j}^{c d i s}-c_{t, j}^{c h} x_{t, j}^{c c h}
\end{array}\right.
$$

where $p_{t, j}^{d i s}, p_{t, j}^{c h}$, respectively, represent the discharge and discharge power of the storage unit in the energy station $j$ at time $t$, and the unit is $\mathrm{kWh} ; h_{t, j}^{d i s}, h_{t, j}^{c h}$ represent the heat release and charging power of the heat storage unit in the energy station $j$ at time $t$, and the unit is $\mathrm{kWh} ; c_{t, j}^{d i s}, c_{t, j}^{c h}$ represent the cold release and charging power of the cold storage unit in the energy station $j$ at time $t$, and the unit is $\mathrm{kWh} ; x_{t, j}^{p d i s}, x_{t, j}^{p c h} \in\{0,1\}$ is the scheduling factor and denotes whether the storage equipment in the energy station $j$ at time $t$ is discharging or charging; $x_{t, j}^{h d i s}, x_{t, j}^{h c h}$, respectively, denote whether the heat storage device in the energy station $j$ at time $t$ is heat release or heat charge; $x_{t, j}^{c d i s}, x_{t, j}^{c c h}$ denote whether the cold storage equipment in the energy station $j$ at time $t$ is cold release or cold charge.

\section{Multi-Time-Scale Cooperative Control Strategy}

The multi-time-scale cooperative control strategy includes two stages: day-ahead economic optimization scheduling and daytime real-time correction. In order to effectively schedule the demand-side response capability system to participate in daytime correction, a two-layer daytime correction algorithm is proposed, which includes upper scheduling and lower management. The flow chart is shown in Figure 4.

The specific process is as follows $[14,15]$ :

(1) System initialization: The optimization goal and scheduling cycle are set according to the actual regional integrated energy system, the user demands, and electric energy storage thermal energy storage system operation constraints. The optimization objective of day-ahead dispatching is the minimum of the operation cost of regional integrated energy system. In the daytime correction, the tie-line power command in the tracking day-ahead scheduling is set as the optimization target.

(2) Day-ahead scheduling: Day-ahead scheduling plan is generated by solving the day-ahead optimization scheduling model according to the day-ahead forecast results of regional comprehensive energy system load, renewable energy output, outdoor environment, and heat from indoor heat source;

(3) Update system status: Update system status according to daytime measured data (system load of 


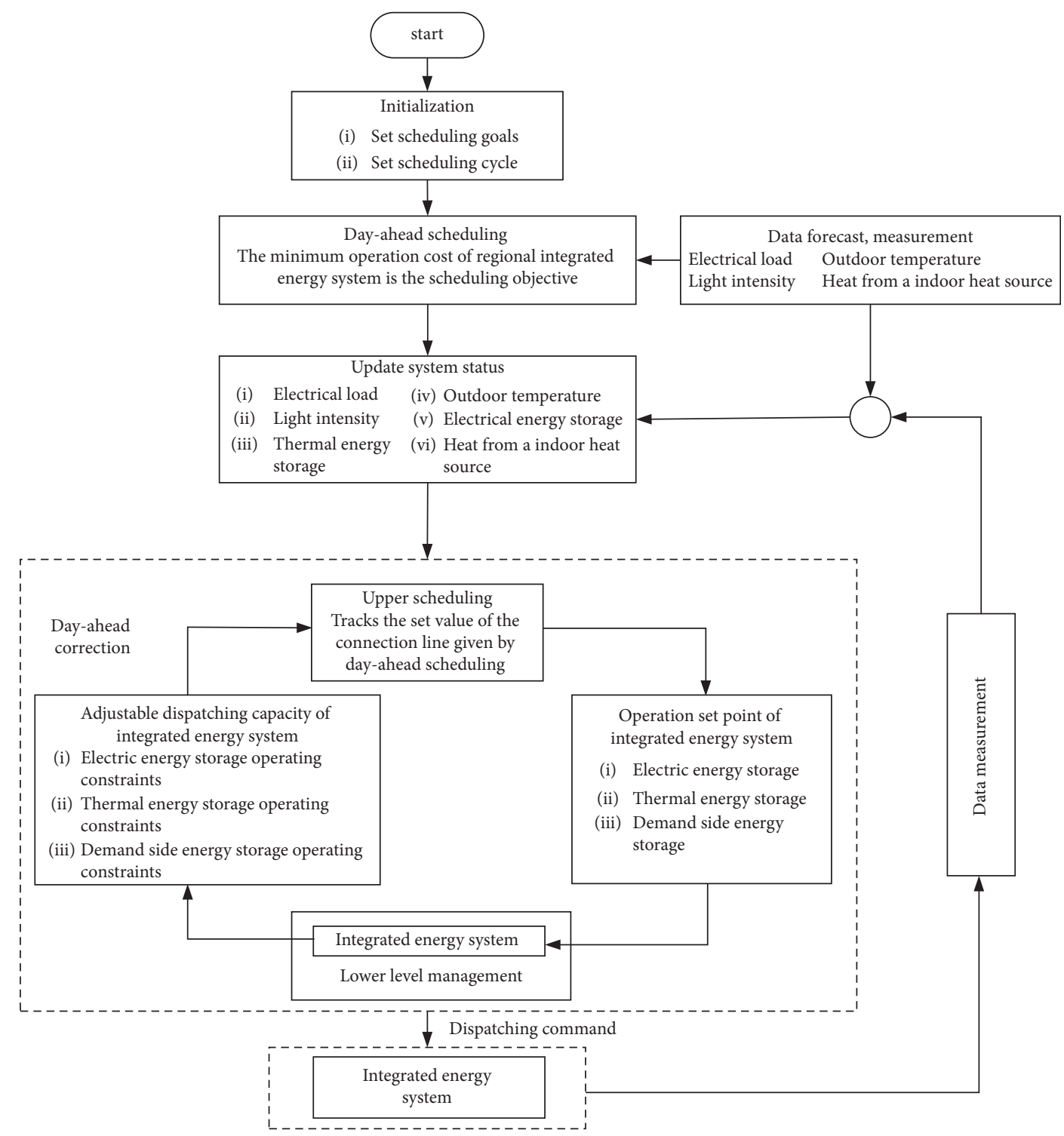

FIGURE 4: Multi-time-scale cooperative control strategy of hybrid energy storage system.

regional comprehensive energy system, output of renewable energy, outdoor environment, and heat from indoor heat source);

(4) Daytime correction: The charge and discharge management of the demand-side response ability is realized by adjusting the indoor temperature of the buildings within the comfortable range of the indoor temperature of the building; in addition, the dispatching is carried out within the schedulable capacity of electric and thermal energy storage systems. Thus, the hybrid cold, hot, and electric energy storage system can be fully scheduled to track the set value of the tie line given by day-ahead dispatching and achieve the goal of suppressing the power fluctuation of the tie line.

\section{Example Analysis}

Taking summer refrigeration scenario as an example, the "source-storage-charge" multiobjective joint optimization regulation of typical CCHP system is studied in this paper. In this paper, the building in the regional comprehensive energy system is set as a single-family office building, with a length of $30 \mathrm{~m}$, a width of $20 \mathrm{~m}$, and a height of $3 \mathrm{~m}$, a total of three floors. $190 \mathrm{~mm}$ single row hole bricklaying is adopted for the external wall of the building, and $25 \mathrm{~mm}$ thermal insulation mortar is used for the inside and outside. The windows are PVC plastic windows, and the glass is ordinary insulating glass. Considering the angle relationship between the direct direction of the sun and the exterior windows of the building, part of the exterior windows being back to the sun and the shading coefficient of the glass, air density $\rho$ and air specific heat capacity ratio $C$ are, respectively, $1.2 \mathrm{~kg} / \mathrm{m} 3$ and $1000 \mathrm{~J} /\left(\mathrm{kg}^{\circ} \mathrm{C}\right)$. Assume that the user's office hours are from $8: 00$ to $20: 00$. Real-time electricity prices are shown in Figure 5. The price of electricity in the figure is the price of electricity purchased from the grid, and the price of electricity sold is multiplied by a certain coefficient, which is 0.8 in this paper. 


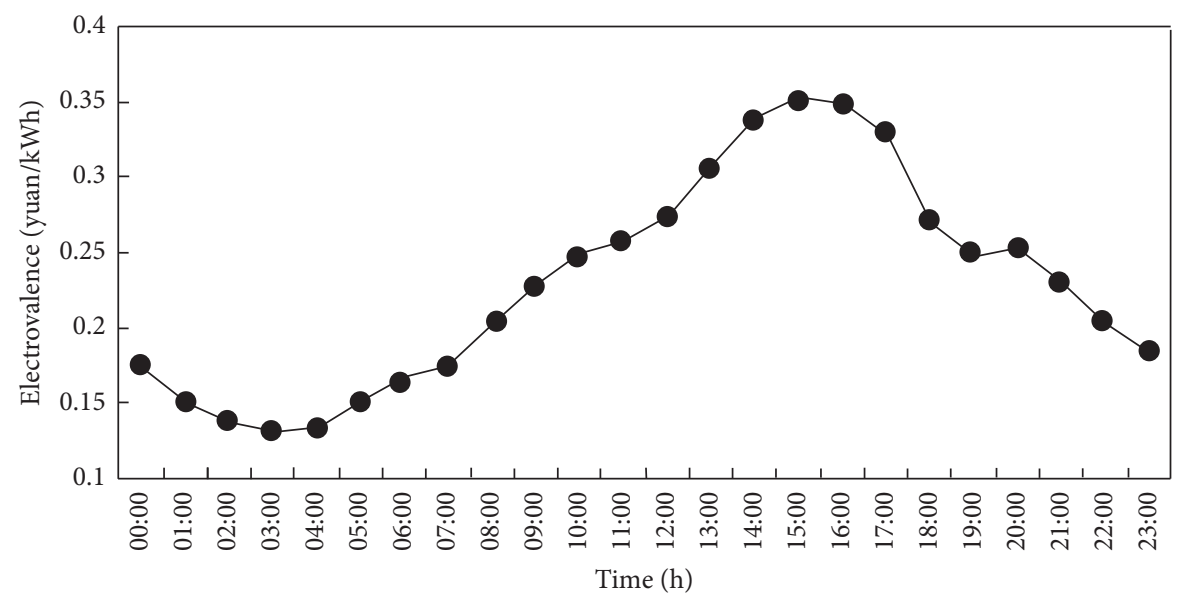

FIGURE 5: Day-ahead spot price.

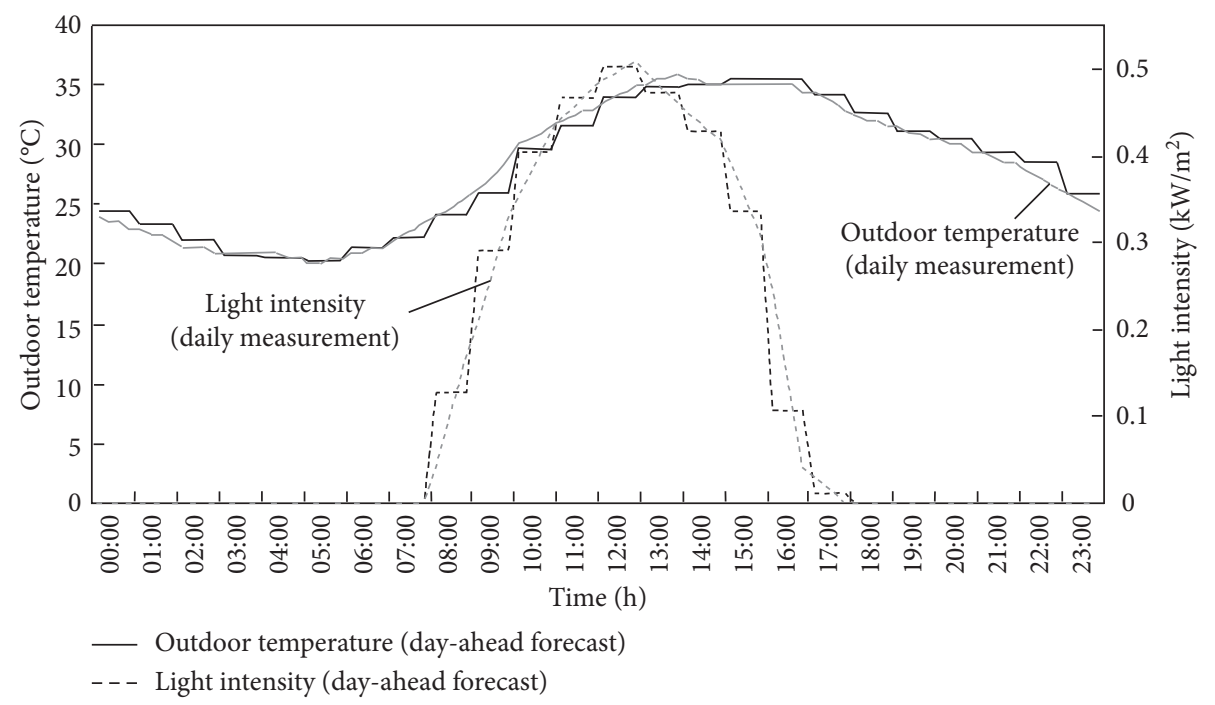

FIGURE 6: Light intensity and outdoor temperature.

The multi-time-scale optimization scheduling analysis of the CCHP supply system in Figure 6 was carried out on the day before and day after. Assume that the user's office time is from $8: 00$ to $20: 00$. A typical daily photovoltaic prediction/ measured curve, daily conventional electricity consumption (excluding refrigeration power consumption) prediction/ measured curve, and heat source prediction/measured curve in the building are shown in Figure 7.

In the scheduling plan, it is assumed that the user can accept the temperature fluctuation within the range of plus or minus $2.5^{\circ} \mathrm{C}$ during working time, and the user's set temperature is $22.5^{\circ} \mathrm{C}$. There is no requirement for indoor temperature during nonworking time. The day-ahead optimization scheduling results of the regional integrated energy system with cold and heat sources and energy storage are shown in Figures 8 and 9.

In order to verify the effect of the proposed multi-time scale optimization scheduling method on suppressing the power fluctuation of the tie line, two comparison scenarios are set as follows:
Scenario 1: According to the day-ahead scheduling plan, the system is modified in real-time during the day. In Scenario 1, the hybrid energy storage system of cold, heat, and electric does not participate in the daytime real-time correction. When there is a shortage of electric/cold power caused by the day-ahead prediction error in the system, all of them take electric energy as supplementary energy. The tieline power of daytime scheduling in this scenario is shown in Figure 10.

Scenario 2: According to the day-ahead scheduling plan and considering the participation of the hybrid energy storage system of cold, heat, and electric in the daytime correction, the power results of the microgrid tie line are shown in Figure 10.

By comparing Scenario 1 and Scenario 2, it is obvious that the tie-line power tracking effect of Scenario 2 is better than that of Scenario 1 after participating in the daytime correction by scheduling the charging and discharging power of the hybrid cold, hot, and electric energy storage system, thus reducing the tie-line power fluctuation of the 


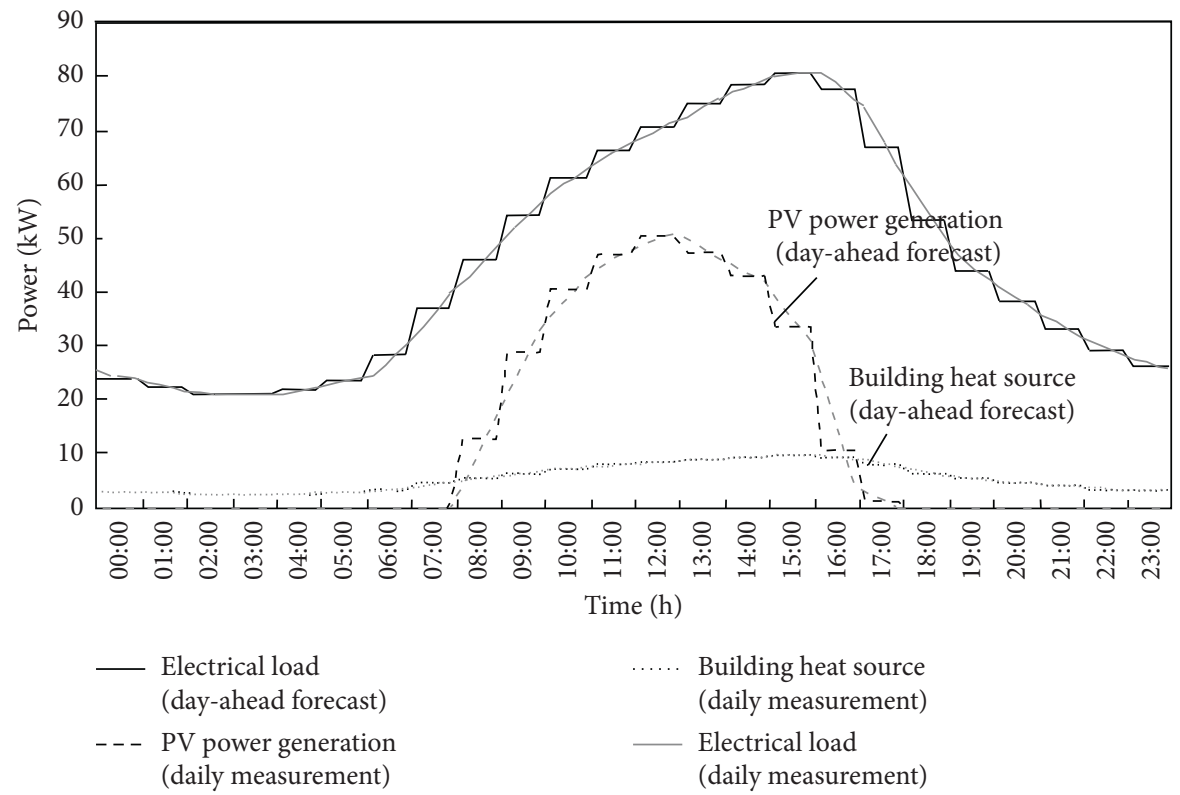

Figure 7: System daily load and DG output curve.

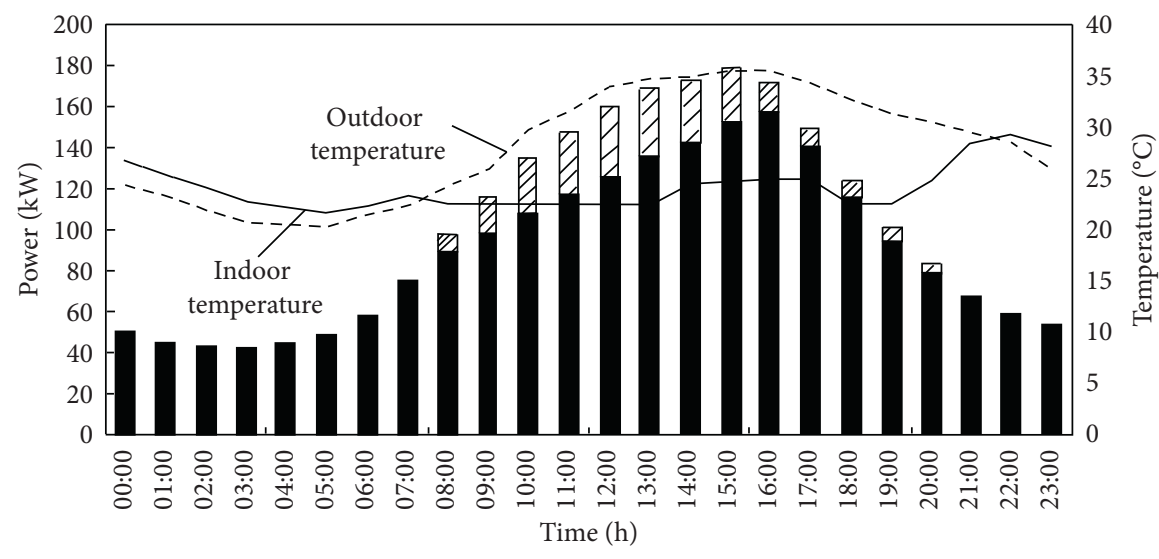

Tie line exchange power

एाIIIA Power consumption of refrigerator

FIGURE 8: Optimal power dispatching.

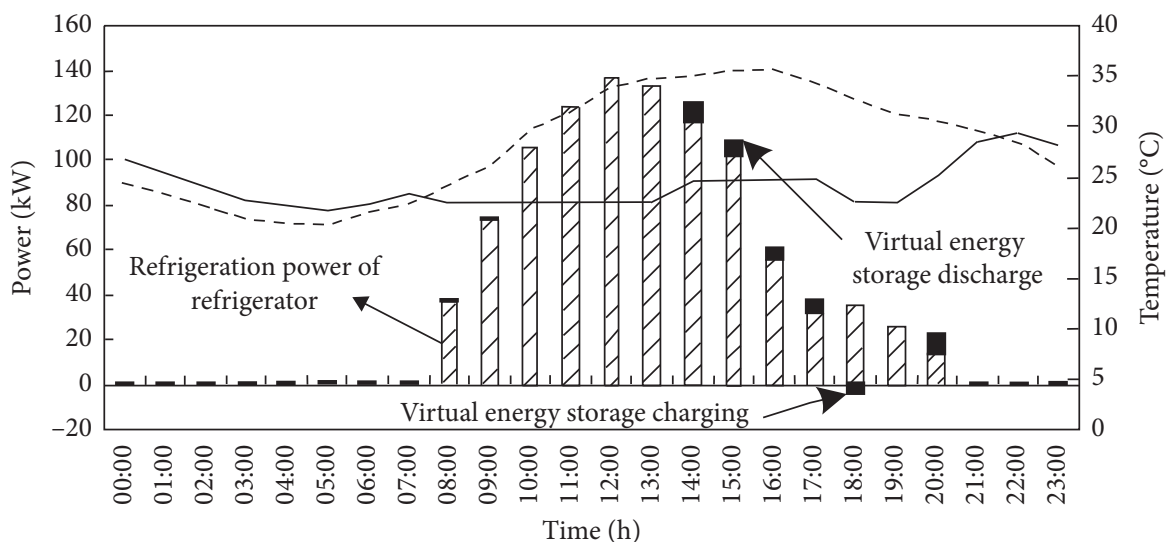

Charging and discharging power of virtual energy storage system

- - - Outdoor temperature

- Indoor temperature

Figure 9: Optimal cooling scheduling. 


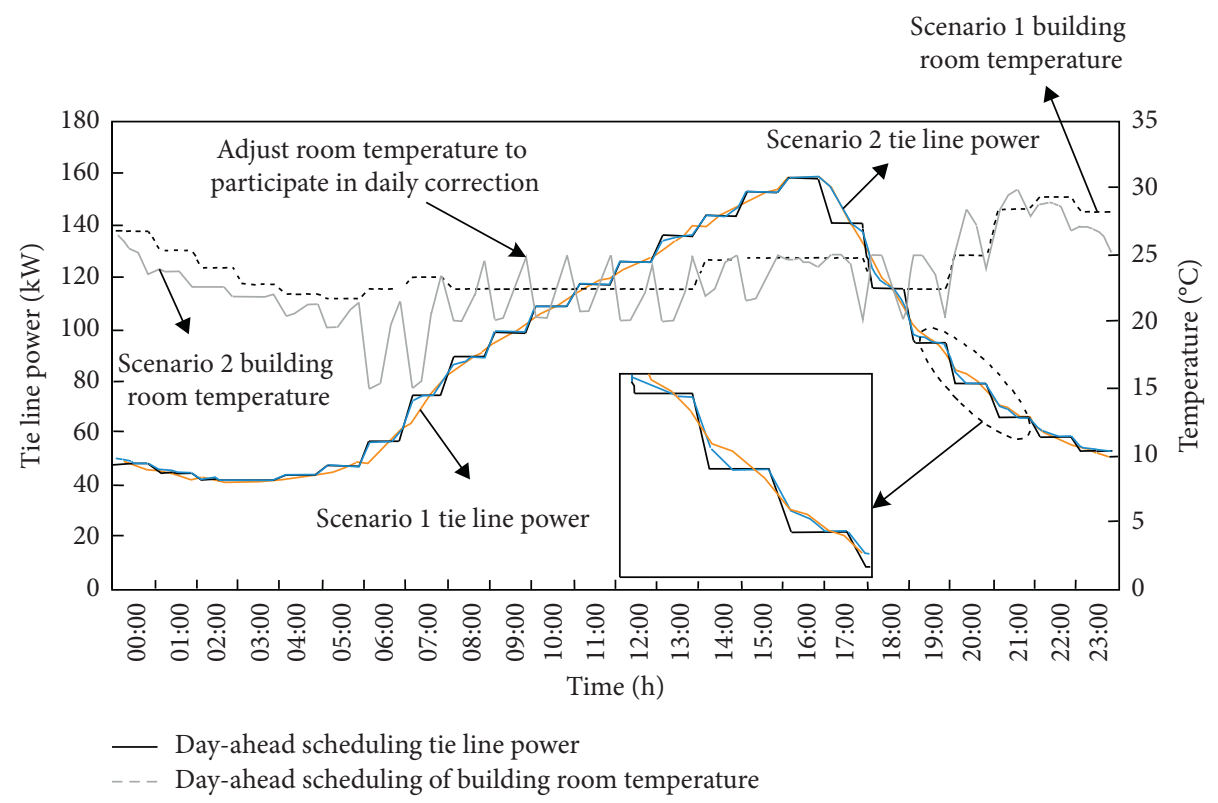

Figure 10: Tie-line power of regional integrated energy system.

regional integrated energy system to a certain extent. At the same time, it reduces the load demand in the peak period of the upstream grid load and plays a role of peak regulation.

\section{Conclusions}

In this paper, the complementary potential of the hybrid energy system and the response priority mechanism of the integrated energy system equipment are analyzed from the aspects of technical and economic factors. The design model of the integrated energy coordinated control is optimized, and the solution analysis is carried out by using the multi-time-scale cooperative control strategy. The optimal scheduling results of multiple time scales of source-storage-load are obtained by example analysis. In this article, through in-depth analysis of the source charge storage, combined with its characteristics and application prospect, for building regional power grid dispatching operation in the future of the energy Internet development new pattern has been carried on the beneficial exploration, and this study provides new scheduling resources for regional power grid scheduling, explores the new grid regulation means, and can alleviate the pressure of the period of the peak load of power grid operation, and improving the safe and stable operation level of power grid is of great significance to the construction of mixed energy system, the promotion of new energy consumption, the increase of the application of energy storage in power grid, and the realization of more sustainable energy management.

\section{Data Availability}

All the data included in this study are available upon request by contacting the corresponding author.

\section{Conflicts of Interest}

The authors declare that there are no conflicts of interest regarding the publication of this paper.

\section{Acknowledgments}

This study was funded by the project Research and Demonstration Application of Key Technologies of Client-Side Energy Control System Based on Smart Energy Service Platform (5400-202018213A-0-0-00).

\section{References}

[1] J. Yang, Y. Lin, J. Chen et al., "Future urban shared electric vehicle development mode," Electric Power Construction, vol. 40, no. 4, pp. 49-59, 2019.

[2] J. LV, W. Pengfei, Y. Liu et al., "Stochastic estimation of grid voltage sag considering the correlation of new energy output," Power Construction, vol. 39, no. 10, pp. 71-81, 2018.

[3] X. Zheng, J. Yu, Y. Zhang et al., "Coordinated optimal control of distributed photovoltaic cluster based on model predictive control," Power Grid and Clean Energy, vol. 35, no. 07, pp. 66-74, 2019.

[4] H. Gao, Q. Xu, K. Zeng et al., "Analysis of source grid load coordination optimization control strategy with multi type distributed generation," Power Engineering Technology, vol. 37, no. 04, pp. 21-26, 2018.

[5] Z. Li, P. Zhang, J. Ma et al., "Multi objective optimization control method for wind storage coordination based on dynamic weighting," Power System Automation, vol. 40, no. 12, pp. 94-99, 2016.

[6] H. Diao, P. Li, J. Wang et al., "Optimal scheduling of integrated energy system considering complementary coordination of electric/thermal energy storage," Acta Electrotechnics, vol. 11, pp. 1-12, 2018. 
[7] Y. Ou, Z. Yuan, C. Lu et al., "Study on optimal operation of cold heat power integrated energy system considering source charge storage multi energy complementation," Power Generation Technology, vol. 41, no. 01, pp. 19-29, 2020.

[8] J. Li, J. Liu, C. Xue et al., "Capacity allocation method of multi energy complementary power generation system with renewable energy," Power Grid Technology, vol. 43, no. 12, pp. 4387-4398, 2019.

[9] T. Ma, B. Jia, Z. Lu et al., "Multi energy complementary coordinated fault recovery method for energy interconnection distribution network based on master-slave game theory," Power Automation Equipment, vol. 40, no. 05, pp. 38-47, 2020.

[10] S. M. Hosseini and M. Dotoli, "Robust optimal energy management of a residential microgrid under uncertainties on demand and renewable power generation," IEEE Transactions on Automation Science and Engineering, vol. 18, no. 02, pp. 618-637, 2021.

[11] I. B. Sperstad and M. Korpås, "Energy storage scheduling in distribution systems considering wind and photovoltaic generation uncertainties," Energies, vol. 12, no. 7, p. 1231, 2019.

[12] A. Barbato and A. Capone, "Optimization models and methods for demand-side management of residential users: a survey," Energies, vol. 7, no. 9, pp. 5787-5824, 2014.

[13] P. Scarabaggio, S. Grammatico, R. Carli, and M. Dotoli, "Distributed demand side management with stochastic wind power forecasting," IEEE Transactions on Control Systems Technology, vol. 17, pp. 1-16, 2021.

[14] S. M. Hosseini, R. Carli, and M. Dotoli, "A residential demand-side management strategy under nonlinear pricing based on robust model predictive control," in Proceedings of the 2019 IEEE International Conference on Systems, Man and Cybernetics, pp. 3243-3248, Bari, Italy, October 2019.

[15] J. S. Giraldo, J. A. Castrillon, J. C. Lopez, M. J. Rider, and C. A. Castro, "Microgrids energy management using robust convex programming," IEEE Transactions on Smart Grid, vol. 10, no. 4, pp. 4520-4530, 2019. 